SCIREA Journal of Information Science

and Systems Science

http://www.scirea.org/journal/ISSS

August 29, 2021

Volume 5, Issue 4, August 2021

\title{
A Model for Evaluating Cloud Computing Benefit for Small Business: Extending DeLone and McLean into the Cloud Era
}

\author{
Charles Flack ${ }^{1}$, Pamila Dembla ${ }^{2, *}$ \\ ${ }^{1}$ Network Transformation Consulting, Smyrna, GA, USA \\ ${ }^{2}$ Information Systems, Kennesaw State University, Kennesaw, GA, USA \\ *Email: pdembla@kennesaw.edu
}

\begin{abstract}
Cloud computing is a new $21^{\text {st }}$ century computing paradigm to provide a diversity of computational services based on a pay-as-you-go, shared service model for all business types across various industry segments. Information system (IS) success has been extensively researched to frame key attributes of an information system or technology to understand its benefit to business. One definition of IS success is the adoption and extensive use of an information system. In the present era of cloud computing, as in former IS eras, successful implementation is critical for achieving business success in all enterprise types. IS success is also described as a lagging multifaceted measure of technology effectiveness for a business. Early adopters of a new technology are a rich resource to determine benefits for later adopters, and this is true for those businesses looking to implement cloud computing. Cloud computing provides clear and definitive business value, and competitive advantages beyond what small business can build on their own, with measurable net benefit. Based on a
\end{abstract}


parsimonious version of DeLone and McLean IS Success Model, the authors of this study have developed a model to evaluate the experiences of small business cloud computing users. The purpose of this model is to define for essential constructs that focuses on the overall cloud quality and experiences that are related to one single dependent construct that assesses the net benefits of cloud computing for small businesses.

Keywords: Cloud computing, DeLone and McLean IS Success Model, small businesses

\section{Introduction}

Cloud computing is a growing information technology (IT) model for providing computing resources and services to individual end users and organizations. Cloud computing is characterized by the ability to rapidly provide and release a variety of resources (applications, servers, storage, networks, and services) with minimal customer IT management involvement or service provider involvement [35]. Common characteristics of cloud computing are ubiquitous network access, rapid elasticity (bidirectional scalability), measured service, ondemand service, multitenancy, and resource pooling regardless of the cloud deployment model [78]. Cloud computing has emerged as a transformational way in which organizations purchase, use, and manage computing resources and services. Cloud computing provides a fundamentally different IT model to procure and deliver IT services. When a business requires a combination of hardware provisioning, software installation, system upgrades, upkeep, data storage, system backups, and comprehensive security, cloud service providers might be responsible for providing any combination [19]. Cloud services have enabled startups and other businesses to focus on core competencies without worrying as much about infrastructure provisioning and management. Key features of cloud computing can provide broad benefits when properly implemented in an enterprise.

Many large corporations are moving rapidly to capitalize on the benefits of cloud-based technologies to provide competitive advantages in their marketplaces. The skepticism and uncertainty executives and business owners felt early on about migrating mission-critical IT systems to the cloud are rapidly diminishing [12]. This skepticism is being replaced with an increased enthusiasm for and heightened expectation of the financial flexibility and liberty that comes from cloud computing services' modularity and pay-per-use approach to 
accessing the latest computational technologies [36]. Since the 2008 recession, organizations must address a dual challenge of maximizing the use of costly IT resources to obtain and maintain their competitive advantage in the marketplace, all while working to diminish the operational and maintenance costs of IT [17]. Many small businesses are similarly enticed by the attributes of cloud computing, but there are many other factors shaping or inhibiting small businesses' selection of cloud computing to support their business [30].

Today's cloud computing services vary in offerings and have differences within the scope of each offering. All cloud computing iterations provide similar enablement capabilities. The usage-based enablement capabilities of cloud computing offer substantial benefits to businesses [6]. They provide the ability to reduce or remove upfront expenses, thereby enabling a lower cost-of-entry and flexibility to adjust capacity as needed to support varying business demand [22]. While experts have a difference of opinion on the precise definition of cloud computing, all agree that it provides a subscription-based, pay-for-use model for businesses to affordably access the latest technology at the lowest price [ 11,19, 22, 23, 24, $34,78]$. This model of computational service is delivered by a third-party service provider that makes computational resources available with the appearance of virtually unlimited capacity [50]. Researchers and industry generally agree on the three major service models of cloud computing [11.19, 22, 23, 24, 34, 35, 78] which are Software-as-a-Service (SaaS), Platform-as-a-Service (PaaS), and Infrastructure-as-a-Service (IaaS). Based on the cloud model, a small business can implement any of these three models (or a combination thereof) to have competitive leverage in the marketplace. Refer to Figure 2 and section 2.1 for a comparative illustration of SaaS, PaaS, and IaaS.

Large enterprises are working to take advantage of the benefits of cloud computing solutions to achieve information system (IS) success. Enterprises that are assessing their IT operations and framing their business case for migrating to cloud services understand the importance of determining the upfront benefits and risks [36]. The top expectation is a reduction in future IS capital expenditures (CapEx) with the ability to redirect those funds to invest in other parts of the business [6,13,26]. In many cases, enterprises achieve these benefits soon after implementation, including acceptance, routinization, and infusion that constitute the diffusion of IS. Other benefits provide scalability, operation efficiencies, compliance, and access to leading-edge technologies that are not cost-effective for businesses to buy and build on their own [36]. These features also show benefits to small businesses, but there are other factors affecting small businesses. Many small businesses operate with limited capital to invest in 
new IS technologies, as well as fund their ongoing upgrades, enhancements, and support. Small businesses operate in considerably different contexts than large enterprises, many with the lack of an IT strategy, limited financial resources, and limited IT skills often under the leadership of a single decision maker (i.e., owner) [24].

\subsection{Small Business Challenges}

To provide a competitive marketplace advantage, available and appropriate cloud computing technologies must be understood to determine how they can successfully fit within the small business operational model. Many small businesses are looking to take advantage of new technologies and computational services provided by third parties to help address their business issues, but risks must be understood. Small businesses realize they need to make key investments in the latest technologies to advance their business, but many have only one opportunity to do it right and to make the best choice. A major obstacle for many small businesses is limited financial capital. With limited capital funds, small businesses have limited latitude in selecting the right IS solution for their businesses. Recent studies show that $78 \%$ of small businesses host IS services in-house whereas $22 \%$ outsource [30]. This presents an opportunity that cloud computing is uniquely positioned to address, although the risk of realizing "efficiency" will be achieved postadoption [26]. Adopting a cloud computing model that does not best fit a business can result in compromised business effectiveness and efficiency. Many small businesses operate with limited financial resources and produce thin profit margins. Understanding the successes of and challenges that small businesses early adopters of cloud computing faced is critical in providing a success model for other small businesses to follow.

\subsection{Importance of Study}

As stated by [19] there might be differences in understanding and expectations between the business and provider about the span, scope, and capabilities of cloud computing services. IT investments by small businesses can be wasted when not implemented properly [14]. For large enterprises, small and medium businesses, governments, nongovernment organizations (i.e., nonprofits), and individuals, cloud-based service reduced initial capital investments and resulted in reduced cost over legacy IT deployments. Investment in cloud computing technology offers benefits that extend beyond cost savings to include flexibility, scalability, accessibility (anytime, anyplace, any device), availability, and virtualization. With the need 
to have services on demand, cloud-based services provide device independency (virtualization) and limit the loss of key data in the event of systems or human failure [43].

Although using cloud computing delivers a number of benefits, enterprises considering the use of the cloud services should make equal effort to quantify its risks to their business [80]. Research conducted by [43] found customers wanted a safe path to cloud adoption with benefit assurances, with clear return on investment (ROI) provided. Regardless of the benefits, haphazard implementation by stakeholders, inadequate business acumen, lack of technical capability, and data security are a few of the risks organizations face in adopting cloud computing services [19]. Some of the issues with cloud-based computing services are confidentiality, information security, legal and regulatory challenges, and protection from malicious attacks as computational services and data are stored in a geographically dispersed environments, generally outside national borders [42].

To achieve cloud computing success, potential risks of security, performance, and availability must be addressed. The associated risk and benefits must be taken into consideration in the resultant IS success framework defined for cloud computing. To relate IS success of cloud computing for the enterprise, the fundamental principles of IS success must be understood. IS success for cloud computing is defined as the adoption and extensive use of cloud-based IS systems by an enterprise with desirable net benefits achieved. The goal of this research is to provide a model to assist small businesses in understanding the possible challenges and successes as a result of implementing cloud computing.

\section{Conceptual Model}

The proposed conceptual model for cloud computing IS success for small businesses (Figure 1) is based on quality (cloud computing quality, comprising service and system quality) driving small business experience (organizational satisfaction and use) yielding overall impact (net benefit) as moderated by overall cost. 


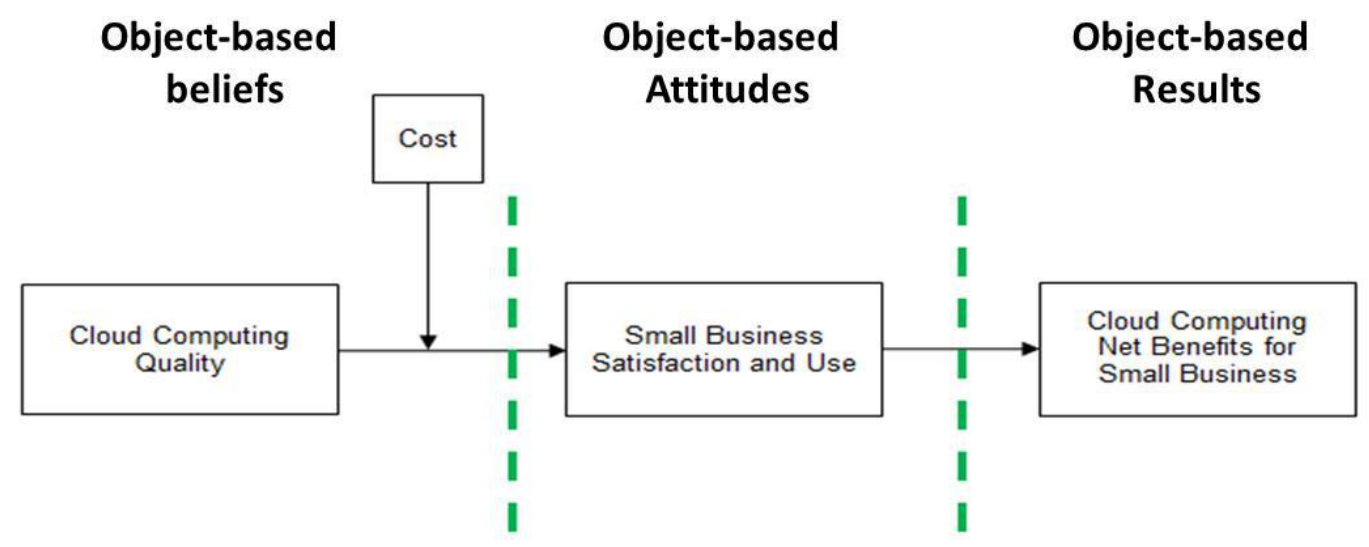

Figure 1. Conceptual model of IS success for cloud computing for small business.

\subsection{Cloud Computing Fundamentals}

Although experts differ on an exact definition of cloud computing, all generally accept the National Institute of Standards and Technology (NIST) definition by [35]. Based on the cloud model a small business desires to exploit, any of the three models (see Figure 2), IaaS, PaaS, SaaS, or a combination thereof, can be used to provide a competitive advantage in the marketplace.

The illustration in Figure 2 compares the computation stack of a traditional enterprise IS environment versus the three cloud-based models. The components noted in dark gray represent those IS assets that are traditionally housed, owned and managed within the enterprise. The components noted in the lighter color represent those IS assets hosted, owned and managed by an outside party but the services provided are consumed by the enterprise. This model also reflects a comprehensive framework what encompasses the cloud provider side, the client side, and in some cases an intermediary [11] 


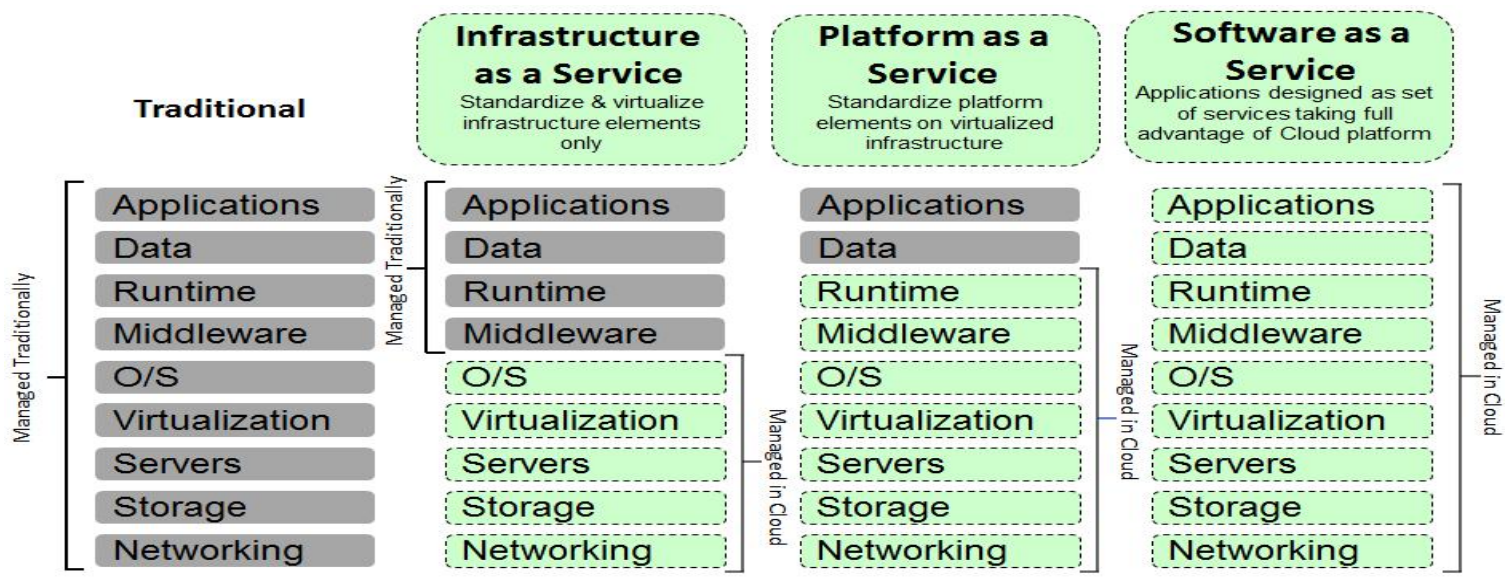

Figure 2. Traditional versus IaaS, PaaS, and SaaS IS models (IBM, 2014).

IaaS provides consumers the ability to deploy, run, and maintain their own software and data, which can include in-house-developed applications, licensed applications, middleware, and a diversity of databases in a cloud environment. IaaS provides the ability for consumers to acquire computational capacity, storage, network, and other fundamental IS resources as required by their organization [35]. The cloud computing service called PaaS is defined as resources provided to consumers to enable the provisioning of application services in the cloud. PaaS provides cloud infrastructure for consumer-programed or licensed applications using the programming languages, libraries, services, and tools supported by the provider [35]. In the PaaS stack, we see where the applications and data components are housed, but owned and managed by the enterprise, whereas everything else is provided by an outside party. SaaS provides the complete IS stack for consumers to use. SaaS is simply paying to use software applications running on a cloud infrastructure [35]. The entire SaaS stack is hosted, owned, and managed by a cloud service provider for enterprise use. Different variants of the traditional as well as IaaS, PaaS, and SaaS delivery models can interoperate and coexist within an IS environment to provide benefit to the enterprise it serves.

Research conducted by [35] theorized that all cloud computing models are composed of five essential characteristics. These five essential characteristics of cloud computing services are as follows: broad network access, resource pooling and sharing, on-demand self-service provisioning, rapid elasticity (i.e., the ability to scale up and down), and metered service. In follow-up research, [23] theorized that cloud computing models incorporated the following additional characteristics: cost reduction; sharing and collaboration; reliability; ease of use; convenience; and security and privacy. 


\subsection{Cloud Computing Marketplace}

The cloud computing industry is made up of diverse providers delivering a plethora of cloudbased services. These providers used different models for delivering cloud-based services, from general purpose to niche markets. On the surface it appears that cloud computing has evolved to a mature industry space, but associated definitions, attributes, and characteristics for cloud computing will continue to evolve [35].

Industry estimated [27] the rate of growth rate of 30\% since 2011 for all cloud services. [27] found 2.3 million net new jobs were created in the cloud computing services industry on an aggregate basis from 2010 to 2015, which is five times the rate of growth of jobs created in the IT industry as a whole. Although there are varying projections of revenue forecast in the cloud computing business sector and revenue generated by those that use it, many agree that it ranks as one of the largest IT transformational trends since the dot-com era [8]

Although the prospective benefits of cloud computing for the enterprise are tremendous, the risk for the enterprise can be equally traumatic, compromising IS success. One of the greatest concerns enterprises have in housing their IT services in the cloud primarily centers on data security and availability [5]. Customers across many industries want assurances that include a clear route to enable firms to use the cloud for high performance and availability but do not increase risks in terms of security and privacy. Research by [42] found the fear of fears over data security, as well as a number of other issues (e.g., vendor lock-in, lack of data visibility, and back-up issues) were a cross-industry concern (government, financial, telecom, media, manufacturing, and retail businesses), but they also found that $74 \%$ perceived cloud computing as highly relevant within their specific sectors. Research found organizations that experienced major data breaches experienced cost for remediation, cost of implementing increased cybersecurity protection, loss of revenue, litigation, and damage to reputation of the enterprise [42].

The ongoing marketing message conveyed by cloud computing providers is the comparison of cloud computing to a service utility, where thoughts of the quality and unwillingness to select a utility rarely arise. The typically compared service utilities are electricity, water, gas, and public telephony services. These utility services are taken for granted and are accessed with such regularity consumers expect them to be available at all times [8]. Cloud computing has yet to rise to the service level standard of these utilities. [7] concluded cloud computing services tend to be used most frequently by specialized IT companies or technology-related 
companies. Many small businesses are challenged by the many aspects of transforming their IT environment to take advantage of cloud technologies. With IaaS, SaaS, and/or PaaS, small businesses are looking to determine which best suit when business model. With the introduction of Internet technologies in the early 1990s, and other technologies such as distributed computing, Web 2.0, high-capacity battery, and pervasive high-speed wireless in the 2000s, small businesses have the ability to take advantage of the latest state-of-the-art computational resources and transact business anywhere in the world. With the use of smart, new, mobile end-user devices (e.g., laptops, tablets, and smartphones) and social media, small businesses can support a larger customer base and broader market. The challenge many small businesses face in this new era is what cloud computing services can help it to achieve IS success based on available technologies and services.

\subsection{Cloud Computing Model for Small Businesses}

It is evident that cloud computing is the future application platform that many IT services providers are rapidly building [34,47], but its widespread use by small businesses has yet to be determined. Its core purpose and advantage remain unnoticed by a wide segment of small businesses, whereas large companies view cloud computing a tool to provide a marketplace advantage and a vehicle to reduce ongoing IT maintenance costs [7]. The cloud computing capabilities must be able to fit and align with the select small business operational model. Moreover, for small businesses to be able to exploit the capabilities cloud computing provides, provisioning cost must be aligned with its business needs.

An effective cloud-centric model for small business will incorporate key attributes. Technical and delivery functionality are the first and critical attributes a cloud computing model must provide to small businesses. Technical and delivery functionality is described as the type of IT services that can be scaled, provisioned, and delivered to the needs of small business. Cloud computing capabilities identified by [26] include business concentration, recyclable infrastructure, mutual problem resolution, business model investigation, coordinating dependencies, and social media effect (e.g., Facebook ${ }^{\mathrm{TM}}$ ). Other capabilities enabled by cloud computing service include agility, innovation and speed, standardized self-service provisioning, pay per use, minimal IT operation burden on users, strong security, elastic scaling, partitioning, replication/mirroring, and failover capabilities, as well as security, monitoring, and multitenancy [47]. 
Business fit is the second key attribute a cloud computing model must provide to small businesses. For small businesses that have the need for IT services but do not have the resources to build and support it to fit their business model, cloud computing can offer a solution. For those businesses looking to develop applications to improve their business model, [26] found that cloud computing enabled businesses to accelerate application development and associated business processes, resulting in faster response organization and improved customer satisfaction. For those enterprises that selected SaaS or PaaS and are part of the Small Business Web (an association of cloud service providers that have come together to build a system of interrelated interoperable software), [21] found a pattern of leveraging the interoperable capabilities of cloud computing, providing capabilities to build the best-ofbreed interoperable systems that can operate at a small business price point. Lastly, according to [26], another pattern of the business value of cloud computing is related to social media and leveraging the convergence of real-time data and social aspects they can generate for the small business.

IS acquisition and expense are the third key attributes a cloud computing model must consider for small businesses. Small businesses could execute strategies that focus on building their own information and communication technology infrastructure, but the resultant solutions would require considerable financial resources, more than what many can afford. Cloud computing makes it more affordable for small businesses to acquire this capability [34]. The manner in which businesses establish their IT environment has advanced from the binary "buy versus build" scenarios. Small businesses have the ability to assemble more complex IT components on the web, which can include building hybrid systems using licensed and/or open-source software, while adopting multiple models of cloud computing.

The fourth key attribute for a cloud-centric model for small businesses deals with business competitive advantage [26]. For those businesses that were able to make the investments in building e-commerce and interactive web applications, they were able to differentiate their products and services from their competitors. Cloud computing services is the latest digital technology that has created opportunities for leveraging new business models and lowering IS costs to create competitive advantages for small businesses, in some cases leveling the playing field [45]. 


\section{Extending IS Success Model to Cloud Computing}

For our research, the e- commerce model of [51] and the website model of [52], both adapted from the updated [16] IS success model, will be used as the basis for the IS success model of cloud computing for small businesses. Basing their research on the DeLone and McLean IS Success Model (SM), [51] assessed their research model's applicability to gauge user satisfaction and technology acceptance. The e-business-related dependent variables associated with the Wixom and Todd model directly relate to key features that reflect qualities and attributes related to cloud computing.

In our research, "information quality" will not be included in our model based on the premise that the small business adopting a cloud-based model is not looking for the cloud service provider to produce information quality, but the small business will be responsible for assuring its own information quality. Our study will include those small businesses that have adopted cloud computing, moved their existing data, and enabled application services in the cloud. The issue of information quality is presumed because the responsibility of the quality of the information resides with the customer and is not produced by the cloud provider.

Within the context of cloud computing, customers, suppliers, and internal users will all consume computational services delivered inside and outside the enterprise via the Internet. Our research intends to affirm that service quality is the essential and critically important measure of cloud computing IS success, due to the nature of service being provided by a third party. The service quality dimension from the [16] original model (see Figure 3) will be reincorporated in our research, although [52] used the [51] and [16] models to show the relationships among SysQ, IQ, and ServQ. We incorporate the precedence relationship between SysQ and ServQ taken from the [52] model. Since SaaS, PaaS, and IaaS are "computational services," we will only assess the causal effects of SysQ on ServQ in our research model.

For our research we define net benefits of cloud computing at the organizational level as the chief measure of small business IS success. To achieve an accurate and effective evaluation of cloud computing net benefits, we will consider well-rounded measures of evaluation. Although the net benefits of cloud computing can be related to IS impact, which is defined as a point-in-time measurement of a flow of net benefits from the IS to date and projected, as perceived by all essential user groups [18], for our research we are assessing the perception of cloud computing net benefits at the organizational level. Through this study our research 
aims to extend understanding about the consequences and drivers of the causality of net benefits, by service quality, organizational satisfaction, and use. Figure 3 shows the resultant combination of the updated Delone and McLean IS SM with the [51] and [52]. models as adapted to model IS success for enterprises that have adopted public SaaS, PaaS, and IaaS cloud computing solutions.

It should be noted in Figure 3 that the perception of system quality is related to service quality in our cloud services-based model for small business. Although few studies have taken into account system quality as an antecedent of service quality [52], other research based on the Delone and McLean IS SM distinguishes service quality from system quality. With many small businesses lacking a dedicated IT staff, the cloud service provider is chiefly responsible for delivering this unified service. For those small businesses that adopted cloud computing, there is immediate benefit; therefore, we posit service quality as an immediate antecedent to net benefit over a traditional in-house IT environment the small business might have in place or be considering. The combination of ServQ and SysQ comprise the notion of what we call "cloud computing service quality" (CCQual), which is the foundation of this research study (see Figure 1). In our research model, ServQ and SysQ are antecedents to organizational satisfaction and use as supported by the research literature [52]. ServQ, a first stage criterion along with organizational satisfaction and use as second stage criterion, leads to cloud computing net benefit (CCNetBen). With the tendency of small businesses to validate a cloud solution in a limited trial before adoption (which is typically provided by cloud service providers), we posit organizational satisfaction with a cloud service and its associated features will precede use $[51,52]$. In our model both perceived organizational satisfaction and use are direct antecedents to net benefits. We posit for small businesses, as organizational satisfaction and use of the cloud service increase, increased net benefit will be achieved.

Based on the type of cloud service used by the small business, we posit that SysQ and ServQ drive organizational satisfaction and use in different ways. We posit that higher perceived organizational satisfaction related to ServQ will occur with small businesses that have adopted SaaS and/or PaaS. We posit that higher perceived organizational satisfaction related to SysQ will occur with small businesses that have adopted IaaS. In some cases, IaaS might drive perceived use higher due to the fact that IaaS permits small businesses to migrate their existing software stack to the cloud with no changes in software features, but with higher availability, reliability, and accessibility. Cost is the singular moderator to be considered 
between ServQ and its immediate successors (organizational satisfaction, use, and net benefits). We believe the cost of the cloud service will moderate organizational satisfaction and use as related to SysQ for SaaS and/or PaaS due to the need for more cloud service provider interaction with small businesses.

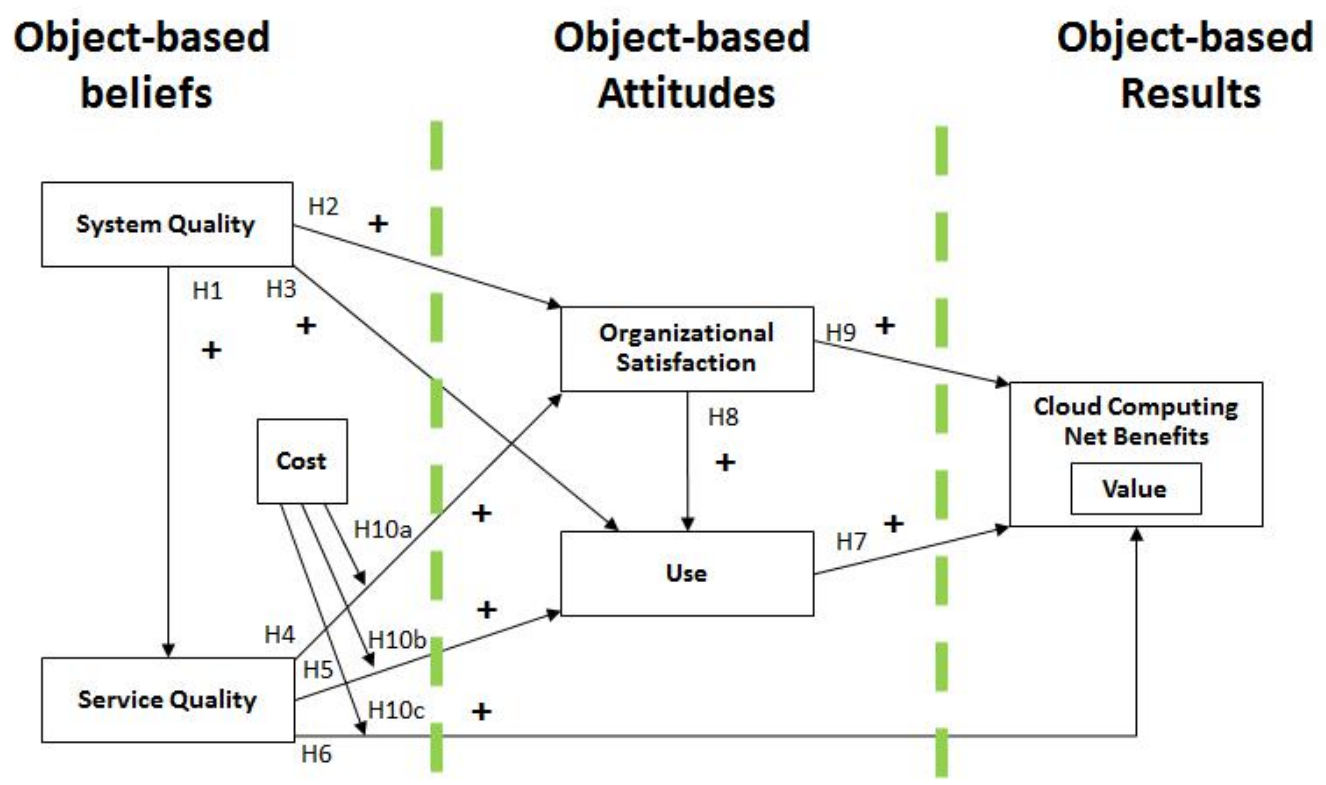

Figure 3. Theoretical model for IS success for cloud computing for small business.

This research will gather quantitative data to confirm the relevance of extending this IS success model to cloud computing and to confirm that the relationships among the constructs will provide significant indication of cloud computing IS success for small businesses. Table 3 shows the body of peer-approved academic and research literature that was reviewed that encompasses this research study. The literature researched chiefly related to studies on cloud computing and information success as related to small business.

Table 1: Definition of Constructs

\begin{tabular}{|l|l|l|}
\hline Construct & Definition & Supporting Citation \\
\hline Service Quality & $\begin{array}{l}\text { Measures the overall perception of support and service characteristics } \\
\text { delivered by the cloud service provider. }\end{array}$ & 16,52 \\
\hline System Quality & $\begin{array}{l}\text { Measures the overall perceptions of the cloud computing system: } \\
\text { availability, usability, adaptability, reliability, and response time (e.g., } \\
\text { download time). }\end{array}$ & $16,51,52$ \\
\hline $\begin{array}{l}\text { Organizational } \\
\text { Satisfaction }\end{array}$ & $\begin{array}{l}\text { Measures the perception of the organization's satisfaction and opinions } \\
\text { of cloud computing system. }\end{array}$ & 16 \\
\hline
\end{tabular}




\begin{tabular}{|l|l|l|}
\hline Construct & Definition & Supporting Citation \\
\hline Use & $\begin{array}{l}\text { Measures the organization's perception of use as measured by } \\
\text { frequency of use, depth of use, duration of use, appropriateness of use, } \\
\text { system dependence, actual use, and self-reported use, among others. }\end{array}$ & 16,41 \\
\hline Cost & $\begin{array}{l}\text { Measures the total cost to initially provision and maintain ongoing } \\
\text { operations of the cloud computing service over a determined time } \\
\text { period based on the consumption-based model. }\end{array}$ & 22,19 \\
\hline $\begin{array}{l}\text { Cloud Computing } \\
\text { Net Benefit }\end{array}$ & $\begin{array}{l}\text { Measures the positive and negative impacts of the cloud computing } \\
\text { business results based on the context and objectives for each cloud } \\
\text { computing investment. }\end{array}$ & 16 \\
\hline
\end{tabular}

The intent of Table 1 is to define the various key constructs from the research literature while Table 2 shows the body of peer-approved academic and research literature that supports the attributes of the constructs that make the research model.

Table 2: Constructs Linked to Scholarly Peer-Approved Literature

\begin{tabular}{|c|c|c|}
\hline Construct & Attribute & Scholarly Peer-Reviewed Literature \\
\hline \multirow[t]{4}{*}{ System Quality } & $\begin{array}{l}\text { Availability and } \\
\text { Reliability }\end{array}$ & $23,23,24,34,35$ \\
\hline & $\begin{array}{l}\text { Adaptability and } \\
\text { Flexibility }\end{array}$ & $6,10,23,35$ \\
\hline & Accessibility & $24,28,29,50$ \\
\hline & Security and Privacy & $5,11,23,24,28,34,50$ \\
\hline \multirow[t]{4}{*}{ Service Quality } & $\begin{array}{l}\text { Accountability and } \\
\text { Auditability }\end{array}$ & $1,11,28 ; 29$ \\
\hline & Responsiveness & $33,20,28$ \\
\hline & Assurance & $6.9 .29,50$ \\
\hline & Trust and Empathy & $1,29,52,24$ \\
\hline
\end{tabular}




\begin{tabular}{|l|l|c|}
\hline Construct & Attribute & Scholarly Peer-Reviewed Literature \\
\hline $\begin{array}{l}\text { Organizational } \\
\text { Satisfaction }\end{array}$ & & $16,40,44$ \\
\hline Use & 16,41 \\
\hline $\begin{array}{l}\text { Cloud Computing } \\
\text { Net Benefits }\end{array}$ & & $16,18,40,49$ \\
\hline Cost & & $17,22,23,31,34,37,39$ \\
\hline
\end{tabular}

\section{1 Dependent Variable}

\subsubsection{Cloud Computing Net Benefit}

For our research, net benefits capture the balance of positive and negative impacts of cloud computing on the small business enterprise. The net benefits of cloud computing are the extent that it contributes to the success of the small business. Net benefits share similarities with and differences from the net impact of other classic computational models used in enterprises. Examples of net benefits are improved decision-making, improved productivity, increased sales, cost reductions, improved profits, market efficiency, consumer welfare, creation of jobs, and economic development [40].

\subsection{Independent Variables}

\subsubsection{System Quality}

In this context, system quality is attributed to the cloud service provider and measures the overall perception of the characteristics of a cloud service. Availability, accessibility, adaptability, reliability, usability, flexibility, scalability, security, and privacy are attributes of system qualities valued by enterprise adopters of cloud computing systems. A research study of mobile data services (MDSs) found perceived system quality is likely to be dependent on the total integrity of the technical architectures of MDSs in sustaining user experience [32].

\subsection{Mediating Variables}

\subsubsection{Service Quality}

Service quality is defined is the primary determiner of satisfaction (user or organizational) with IT service delivery $[18,48,52]$. For our research, service quality is defined as the 
overall and comprehensive services delivered by the cloud computing service provider. Its importance is greater since the consumer of services is the entire enterprise and its customers. Service provider tangibles, plus the capabilities to deliver reliable and responsive service while providing assurance and empathy, are five dimensions of service quality required by organization [9]. With previous generation IT systems, service quality was advanced to be a chief antecedent to user satisfaction with IT service [48]. Service quality can also be correlated to service level. Service level is the cloud provider's ability to provide a stable operational environment where services are available to support the customer's business during the customer's normal business operational hours, and as needed at during other times [28].

\subsubsection{Organizational Satisfaction}

In their early research, [44] found that the difference between successful and failed implementations of IS is related to user satisfaction and involvement. Their research illustrates the relevance of some nontechnical variables in system implementation [44]. Their research studied the deployment of an identical information management system in two separate divisions of the same company. They found the difference between the success and failure of the two separate implementations centered on the attitudes of those involved in their use, which directly related to their satisfaction and dissatisfaction, respectively. The satisfaction of the users of the successful information management system implementation was significantly related to individual performance and performance visibility, and the perceived urgency and importance of the IS being implemented [44]. As posited earlier by [16], greater system quality is expected to lead to greater user satisfaction.

\subsubsection{Use}

Regardless of the enterprise type, [39] determined one of the key benefits of cloud computing is in its ease of provisioning, administration, and use through a web browser and that it is intuitive for users. For this research, we define use as in "system use" as noted by [41]. System use is the extent to and manner in which users and customers use the capabilities of an IS [41]. This is more correlated to the "amount of use" as espoused by [25]. There are many attributes of system use that have been measured (i.e., frequency, depth, duration, appropriateness, dependence, actual, self-reported, etc. [41]. As posited by [16], a highquality IS is characterized by increased use, higher user satisfaction, and positive net benefits. Based on the cloud solution selected by a small business, we believe this to be true. In the 
area of cloud computing, use will be defined as a construct that measures enterprise services hosted in the cloud computing environment for enterprise use, as well as customer-facing services hosted in the cloud.

\subsubsection{Moderating Variable: Cost}

Using the cloud to run applications provides many technical advantages and results in significant cost savings when compared to running them on local managed servers [23]. The "cost of entry" with on-premises software presence is very high, whereas with cloud computing, it is comparably lower [39]. Cloud computing offers the ability to rapidly scale up and down the IT services needed for an organization on a pay-per-use pricing model, while reducing overall IT management costs and driving the utilization to $100 \%$ of the contracted services $[22,31]$. PaaS eliminates upfront IT investment costs, reduces time and minimizes work for setting up a running environment, and removes upgrade and maintenance tasks when compared to the traditional IT approaches [23].

With cloud computing, small businesses have access to competitive computational tools - the same ones used by large enterprises that were not available to small businesses in the past. Investment in licenses, infrastructure maintenance, and upgrades lies with the cloud application service provider, not the user [39]. The service is usually paid for from the operations budget (OpEx) - because there is no capital expenditure (CapEx) [34]. The basic premise of cloud computing is small businesses can lease the required computing, storage, and communication resources at a lower cost to support their business needs from a large service provider that possesses these assets and is connected to the Internet.

\section{Hypothesis Development}

\subsection{System Quality as Related to Service Quality}

The schema that $\{52]$ posited on website content proposes a relationship between SysQ and ServQ. The basis for this research is that SysQ will influence one's belief about ServQ as it relates to IS success with cloud computing. The perception of cloud computing service quality simplifies the complexities, as well as enhances and extends the benefit of the cloud computing system. For the benefit of small businesses, there is a causal relationship between system quality and service quality, hence we hypothesize the following: 
H1: The perception of system quality positively affects the perceived service quality of cloud computing services for small businesses.

\subsection{System Quality as Related to Organizational Satisfaction}

As discussed in their e-services study, [52] found that SysQ and ServQ had a significant and positive relationship with their direct corresponding system satisfaction (SysSAT) and service satisfaction (SSAT). For our model, system and service satisfaction are integrated into a singular satisfaction construct we call "organizational satisfaction." When users participate in selection and development activities of an IS system, organizational satisfaction and system quality are higher [44]. Small business's organizational satisfaction with cloud computing system quality is an essential component of overall success and provides the core basis for cloud computing technology adoption. The relationship between system quality and organizational satisfaction is hypothesized as follows:

$\mathrm{H} 2$ : The perception of system quality positively affects organizational satisfaction in cloud computing services for small businesses.

\subsection{System Quality as Related to Use}

System quality influences and results in increased system usage. In a postadoption usage study of a cloud-based MDSs, [32] determined the elements to increase usage include variables related to system environment or system quality (e.g., access speed and reliability, interface design), cost-related perceptions (e.g., pricing and uncertainty in usage cost), and user attributes (e.g., usage skill or self-efficacy). Small businesses' organizational use of cloud computing services will increase as business results increase even if system quality remains the same; the relationship between system quality and organization use is noted in the following hypothesis:

H3: The perception of system quality positively affects the degree of use of cloud computing services for small businesses.

\subsection{Service Quality as Related to Organizational Satisfaction}

As discussed in their e-services study, [52] found that ServQ had a significant and positive relationship with their direct corresponding service satisfaction (SSAT) construct. For our model, system and service satisfaction are integrated into a singular satisfaction construct we call "organizational satisfaction." Research by [26] found that improved financial services 
and the quality of those services resulted in improved customer satisfaction. On this premise we base the following hypothesis:

H4: The perception of service quality positively affects the degree of organizational satisfaction with cloud computing services for small businesses.

\subsection{Service Quality as Related to Use}

Use of an IS is, arguably, the most critical variable in the entire repertoire of empirical and behavioral studies [48]. Previous studies on continued IS usage have examined the influence of software service quality on satisfaction and the intentions of continued IS usage. Cloud computing services that incorporate unique services technologies to improve overall small business organizational use. Productive and continual organizational use of a cloud computing service by a small business is essentially dependent on service quality. On this basis we establish the following hypothesis:

H5: The perception of service quality positively affects the degree of use of cloud computing services for small businesses.

\subsection{Service Quality as Related to Net Benefits}

[49] found small businesses that focused on improving services to their clients and leveraged technology to do so improved their customer loyalty, retention and resultant profitability. Although those small businesses had a less strategic view and limited budgets than large business, they were more reactive to near-term business needs than long-term goals [49]. With cloud computing in the area of responsiveness, the service is provided almost instantaneously when it is contracted with a cloud service provider; this enhances enterprise agility. Beyond traditional IS technology, cloud computing service provides a foundational net benefit for small businesses. On this basis we establish the following hypothesis:

H6: The perception of service quality positively affects the perceived net benefits of cloud computing services for small businesses.

\subsection{Use as Related to Net Benefits}

Literature suggests that cloud computing use is driven by usage-based pricing; on-demand (self-provisioning), ubiquitous access; convenience; ease of provisioning; feature and functionality; and the ability to provide a competitive advantage. Cloud services allow small business users access capacity exactly when they need it [22], and they only pay for the consumption of those resources required. Regardless of the measure of use, as small 
businesses consume cloud computing services, the net benefits are realized soon after adoption. On this understanding we base the following hypothesis:

H7: The degree of use of a cloud solution positively affects overall net benefits of cloud computing for small businesses.

\subsection{Organizational Satisfaction as Related to Use}

[16] postulated higher expected system quality leads to higher user satisfaction and use. In a process sense, use must precede organizational satisfaction, but positive experience with use will lead to greater organizational satisfaction in a causal sense [16]. Similarly, increased user satisfaction will lead to increased intention to use and thus use [16]. Small business's trepidation is overcome after the adoption of cloud computing services when business results begin to be realized and satisfaction increases, which results in increased use. From this, we base the following hypothesis:

H8: The organizational satisfaction of a cloud solution positively affects overall cloud computing use for small businesses.

\subsection{Organizational Satisfaction as Related to Net Benefit}

The organizational satisfaction with cloud computing is multidimensional like cloud computing itself and results in net benefits. The benefits realized by a large academic medical center in Atlanta are as follows: 50\% decrease in Internet service provider costs; 30\% reduction in annual hardware costs; $60 \%$ decrease in archive storage costs; reduced risk through encryption, firewalls, and intrusion detection; improved HIPAA privacy and security compliance; and IT staffing burdens eliminated [42]. As small business satisfaction increases with the system and service quality of cloud computing services after adoption, business benefits begin to be realized. To provide small business ongoing organizational satisfaction, net benefits should be continually realized, as noted in the following hypothesis:

H9: The organizational satisfaction with a cloud solution positively affects the overall net benefits of cloud computing for small businesses.

\section{10a Cost as Related to Organizational Satisfaction}

Cloud-based systems, due to their shared infrastructure and resource model, provide positive cost savings (e.g., reduced cost) to small businesses, simultaneously reducing the entry point (switching cost) to adopt it as well as normalize IT cost expenditures over time, therefore resulting in positive (e.g., increased) organizational satisfaction [23]. We assume that the 
degree of cost will have a moderating effect on the relationship between perceived service quality and organizational satisfaction, and a negative moderating effect on the relationship between perceived service quality and organization dissatisfaction response. The moderating relationship of cost associated with the relationship between service quality and organizational satisfaction provides the basis for the following hypothesis:

H10a: With cloud computing services with relatively lower costs, there will be a stronger relationship between perceived service quality and organizational satisfaction with small businesses than with cloud computing services with relatively higher costs.

\subsection{0b Cost as Related to Use}

Cloud computing pricing models are positively related (e.g., cost aligned) to usage-based pricing where computing resources are paid for based on the rate of consumption. Cloud computing pricing models are similar to usage-based pricing where computing resources are paid for based on the rate of consumption or cost is discounted based on negotiated volume. Small business use is intensified when the consumption of the cloud computing service is moderated by lower cost. The moderating relationship of cost associated with the relationship between service quality and use provides the basis for the following hypothesis:

H10b: With cloud computing services with relatively lower costs, there will be a stronger relationship between perceived service quality and use for small businesses than with cloud computing services with relatively higher costs.

\subsection{0 c Cost as Related to Net Benefit}

[23] identified that the low entry cost for small firms using cloud computing resulted in a positive effect on small business convenience and economic benefits (e.g., net benefit). Cloud computing net benefit is positive for small businesses over a traditional IT service delivery model as it is less in overall cost (positive), both postadoption and over the life of the cloud computing service. The moderating relationship of cost associated with the relationship between service quality and net benefits provide the basis for the following hypothesis:

H10c: With cloud computing services with relatively lower costs, there will be a stronger relationship between perceived service quality and perceived net benefits for small businesses than with cloud computing services with relatively higher costs. 


\section{Methodology}

This research will use retrospective experience methodology to explore the experiences of small businesses that use some form of cloud computing. The decision is to collect data from respondents from small businesses was based on the high prevalence of business challenges [30] and perceptions of benefit [23]. This methodology was determined appropriate for the current study, as it involves asking respondents to complete scaled responses related to questions involving their experiences and challenges that took place during and after cloud computing implementation.

Using the [51] and [52] validated survey instruments as a base to work from, the intended survey questions will map to the associated constructs, and their associated hypotheses will be tested. Our methodological approach will utilize a Qualtrics ${ }^{\odot}$ small business panel to gather our final research data. Only one primary individual will be targeted in each of the small businesses surveyed. This select individual will be either the owner, operator, CIO, president, or founder of the targeted small business, as validated by the survey instrument. This person will have the most knowledge of cloud computing services implemented in their enterprise.

Cloud computing includes a plethora of offerings, as noted by [26], that can be purchased and used independently or in a myriad of combinations. When different cloud computing services are grouped together as "XaaS" offerings, they include the previously stated cloud service offerings. They extend to but are not restricted to Storage-as-a-Service (i.e., STaaS), Application-as-a-Service (AaaS), Network-as-a-Service (NaaS), and Infrastructure-as-aService (IaaS) [26]. This research will focus on the public SaaS, PaaS, and IaaS cloud computing models, and not private, community, or hybrid cloud computing models.

\section{Discussion and Conclusion}

The purpose of this research study was to create a model that can be used by small businesses to determine the benefits of a particular cloud computing solution before adoption, based on the efforts of select small businesses that were early adopters of cloud computing. This model has framed the essential features and attributes. The focus of the primary success constructs associated with overall cloud quality, experience, and benefit, we believe will yield to an 
enhanced IS success model calibrated for small businesses and targets specific cloud computing services attributes that align with their business requirements and success criteria. In summary, this research sought to define a model that can measure the IS success and net benefits achieved by small businesses that use cloud computing. This model, we believe, can be used to evaluate the aggregated cloud computing experiences of small businesses with each of the major three different cloud computing types. By applying this model, we believe cloud computing service providers can gain insight on small businesses' cloud computing experiences to tune their business model to better exploit this market segment and to grow their business. With cloud computing being at the epicenter of this era in delivering IS services across a spectrum of business segments, this model will be useful in determining the IS success and net benefits to cloud computing users for years to come. Applying this model across all segments of small businesses, there are expected to be different experiences encountered especially those in different industry segments and countries. The intent of this research model is intended to serve as a basis for future research in IS success and cloud computing, demonstrating the extendibility of D\&M 2014, and becoming a catalyst to expand the knowledge base for both practitioners and academics in future years.

\section{References}

[1] Abbadi, I. M. (2013). A framework for establishing trust in cloud provenance. International Journal of Information Security 12(2), 111-128 (doi: 10.1007/s10207-0120179-0).

[2] Al-Johani, A. A., and Youssef, A. E. 2013. "A framework for ERP systems in SME based on cloud computing technology," International Journal on Cloud Computing: Services and Architecture 3 (3, pp. 1-14 (doi: 10.5121/ijccsa.2013.3301).

[3] Alshare, K. A., Freeze, R. D., Lane, P. L., and Wen, H. J. 2011. "The impacts of system and human factors on online learning systems use and learner satisfaction," Decision Sciences Journal of Innovative Education 9(3), pp. 437-461.

[4] Anderson, E., Nag, S., Singh, T. J., Sood, B., Hare, J., Eid, T., Dharmasthira, Y., Swinehart, H. H., Eschinger, C., Wurster, L. F., and Yeates, M. 2015. "Forecast analysis: Public cloud services, worldwide, 1Q15 update," No. G00277763, , Gartner, pp. 1-22. 
[5] Anthes, G. 2010. "Security in the cloud," Communications of the ACM 53(11), pp. 16-18 (doi: 10.1145/1839676.1839683).

[6] Armbrust, M., Fox, A., Griffith, R., Joseph, A. D., Katz, R., Konwinski, A., Lee, G., Patterson, D., Rabkin, A., Stoica, I., and Zaharia, M. 2010. "A view of cloud computing," Communications of the ACM 53(4), pp. 50-58.

[7] Budriene, D., and Zalieckaite, L. 2012. "Cloud computing application in small and medium-sized enterprises," Issues of Business and Law (4), pp. 119-130.

[8] Buyya, R., Yeo, C. S., and Venugopal, S. 2008. "Market-oriented cloud computing: Vision, hype, and reality for delivering IT services as computing utilities," in High Performance Computing and Communications, 2008. HPCC'08. 10th IEEE International Conference on, IEEE, pp. 5-13 (available at http://ieeexplore.ieee.org/xpls/abs_all.jsp?arnumber=4637675).

[9] Buyya, R., Yeo, C. S., Venugopal, S., Broberg, J., and Brandic, I. 2009. "Cloud computing and emerging IT platforms: Vision, hype, and reality for delivering computing as the 5th utility," Future Generation Computer Systems 25(6), pp. 599-616 (doi: 10.1016/j.future.2008.12.001).

[10] Cheng, F., Yang, S. L., Akella, R., and Tang, X. T. 2011. "A meta-modelling service paradigm for cloud computing and its implementation," South African Journal of Industrial Engineering 22(2), pp. 151-160.

[11] Clarke, R. 2010. "User requirements for cloud computing architecture," Presented at the In 2010 10th IEEE/ACM International Conference on Cluster, Cloud and Grid Computing (CCGrid), IEEE, pp. 625-630 (doi: 10.1109/CCGRID.2010.20).

[12] Columbus, L. 2013. "CIOs on cloud computing adoption: Conquer complexity and help us grow," Forbes (available at http://www.forbes.com/sites/louiscolumbus/2013/07/01/cios-on-cloud-adoption-conquercomplexity-and-help-us-grow/).

[13] Creeger, M. 2009. "CTO roundtable: Cloud computing," Communications of the ACM 52(8), pp. 50-56.

[14] Dai, W. 2009. "The impact of emerging technologies on small and medium enterprises (SMEs)," Journal of Business Systems, Governance and Ethics 4(4), pp. 53-60. 
[15] Davenport, T. H. 1998. "Putting the enterprise into the enterprise system," Harvard Business Review 76(4), pp. 121-131.

[16] DeLone, W. H., and McLean, E. R. 2003. "The DeLone and McLean Model of information systems success: A ten-year update," Journal of Management Information Systems 19(4), pp. 9-30.

[17] Dutta, A., Peng, G. C. A., and Choudhary, A. 2013. "Risks in enterprise cloud computing: The perspective of IT experts,” Journal of Computer Information Systems 53(4), pp. 3948.

[18] Gable, G. G., Sedera, D., and Chan, T. 2008. "Re-conceptualizing information system success: The IS-impact measurement model," Journal of the Association for Information Systems 9(7), pp. 1-32.

[19] Garrison, G., Kim, S., and Wakefield, R. L. 2012. "Success factors for deploying cloud computing," Communications of the ACM 55(9), pp. 62-68 (doi: 10.1145/2330667.2330685).

[20] Gold, J. 2012. "Protection in the cloud: Risk management and insurance for cloud computing," Journal of Internet Law 15(12), pp. 1-28.

[21] Gray, P. H., Parise, S., and Iyer, B. 2011. "Innovation impacts of using social bookmarking systems," MIS Quarterly 35(3), pp. 629-643.

[22] Grossman, R. L. 2009. "The case for cloud computing," IT professional 11(2), pp. 23-27.

[23] Gupta, P., Seetharaman, A., and Raj, J. R. 2013. "The usage and adoption of cloud computing by small and medium businesses," International Journal of Information Management 33(5), pp. 861-874 (doi: 10.1016/j.ijinfomgt.2013.07.001).

[24] Haselmann, T., and Vossen, G. 2011. "Software-as-a-service in small and medium enterprises: An empirical attitude assessment," in Web Information System EngineeringWISE 2011, Berlin, Germany: Springer, pp. 43-56 (available at http://link.springer.com/chapter/10.1007/978-3-642-24434-6_4).

[25] Iivari, J. 2005. "An empirical test of the DeLone-McLean model of information system success," ACM Sigmis Database 36(2), pp. 8-27. 
[26] Iye, E. K., Krishnan, A., Sareen, G., and Panda, T. 2013. "Sectorial adoption analysis of cloud computing by examining the dissatisfied landscape," Electronic Journal of Information Systems Evaluation 16(3), pp. 211-219.

[27] Jain, V., and Gupta, A. 2012. "Cloud computing: Concepts, challenges and opportunities for financial managers in India," Amity Global Business Review (7), pp. 22-29.

[28] Kalyvas, J. R., Overly, M. R., and Karlyn, M. A. 2013. "Cloud computing: A practical framework for managing cloud computing risk--Part I," Intellectual Property \& Technology Law Journal 25(3), pp. 7-18.

[29] Ko, R. K., Jagadpramana, P., Mowbray, M., Pearson, S., Kirchberg, M., Liang, Q., and Lee, B. S. 2011. "Trustcloud: A framework for accountability and trust in cloud computing," in 2011 IEEE World Congress on Services (SERVICES), IEEE, pp. 584-588 (available at http://ieeexplore.ieee.org/xpls/abs_all.jsp?arnumber=6012795).

[30] Krell, E. 2011. “The state of small business,” Baylor Business Review 30(1), pp. 4-9.

[31] Kudtarkar, P., DeLuca, T. F., Fusaro, V. A., Tonellato, P. J., and Wall, D. P. 2010. "Cost-effective cloud computing: A case study using the comparative genomics tool, roundup," Evolutionary Bioinformatics (6), pp. 197-203 (doi: 10.4137/EBO.S6259).

[32] Lee, S., Shin, B., and Lee, H. G. 2009. "Understanding post-adoption usage of mobile data services: The role of supplier-side variables," Journal of the Association for Information Systems 10(12), pp. 860-888.

[33] Mahesh, S., Landry, B. J. L., Sridhar, T., and Walsh, K. R. 2011. "A decision table for the cloud computing decision in small business," Information Resources Management Journal 24(3), pp. 9-25 (doi: 10.4018/irmj.2011070102).

[34] Marston, S., Li, Z., Bandyopadhyay, S., Zhang, J., and Ghalsasi, A. 2011. "Cloud computing-The business perspective," Decision Support Systems 51(1), pp. 176-189 (doi: 10.1016/j.dss.2010.12.006).

[35] Mell, P., and Grance, T. 2010. "The NIST definition of cloud computing," Communications of the ACM 53(6), p. 50.

[36] Miranda, S. 2013. "ERP in the cloud: CFOs see the value of running enterprise applications as a service," Financial Executive 29(1), pp. 65-66. 
[37] Nanath, K., and Pillai, R. 2013. "A model for cost-benefit analysis of cloud computing," Journal of International Technology \& Information Management 22(3), pp. 93-117..

[38] O’Sullivan, D. 2009. “The Internet cloud with a silver lining," Manager: British Journal of Administrative Management (66), pp. 20-21.

[39] Petter, S., DeLone, W. H., and McLean, E. R. 2008. "Measuring information systems success: Models, dimensions, measures, and interrelationships," European Journal of Information Systems 17(3), pp. 236-263 (doi: 10.1057/ejis.2008.15).

[40] Petter, S., DeLone, W. H., and McLean, E. R. 2013. "Information systems success: The quest for the independent variables," Journal of Management Information Systems 29(4), pp. 7-62 (doi: 10.2753/MIS0742-1222290401).

[41] Rajendran, J. 2013. "What CFOs should know before venturing into the cloud," $H F M$ (Healthcare Financial Management) 67(5), pp. 40-43.

[42] Rawal, A. 2011. "Adoption of cloud computing in India," Journal of Technology Management for Growing Economies 2(2), pp. 65-78.

[43] Robey, D., and Zeller, R. L. 1978. "Factors affecting the success and failure of an information system for product quality," Interfaces 8(2), pp. 70-75.

[44] Sako, M. 2012. "Business models for strategy and innovation," Communications of the ACM 55(7), pp. 22-24 (doi: 10.1145/2209249.2209259).

[45] Samson, Y., and McDowall, R. D. 2013. "Cloud computing: How to choose the right cloud supplier," Spectroscopy 28(12), p. 15.

[46] Smith, R. 2009. "Computing in the cloud," Research Technology Management 52(5), pp. $65-68$.

[47] Sun, Y., Fang, Y., Lim, K. H., and Straub, D. 2012. "User satisfaction with information technology service delivery: A social capital perspective," Information Systems Research 23(4), pp. 1195-1211 (doi: 10.1287/isre.1120.0421).

[48] Wilkins, C. 2009. "The influence of net benefits on collective, innovation, configural system use: A case study of small-to-medium enterprises," The Electronic Journal of Information Systems Evaluation 12(2), pp. 187-198.

[49] Wittow, M. H., and Buller, D. J. 2010. "Cloud computing: Emerging legal issues for access to data, anywhere, anytime," Journal of Internet Law 14(1), pp. 1-10. 
[50] Wixom, B. H., and Todd, P. A. 2005. "A theoretical integration of user satisfaction and technology acceptance," Information Systems Research 16(1), pp. 85-102 (doi: 10.1287/isre.1050.0042).

[51] Xu, J., Benbasat, I., and Cenfetelli, R. 2013. "Integrating service quality with system and information quality: An empirical test in the e-Service context," MIS Quarterly 37(3), pp. $777-794$. 